\title{
Evaluating the Building Technology Stimulus Initiative Offered by Ministry of Housing within the Kingdom's Vision 2030
}

\author{
Nujud K. Alangari ${ }^{1} \&$ Waleed S. Alzamil ${ }^{2}$ \\ ${ }^{1}$ Architecture and Building Science, College of Architecture and Planning, King Saud University, Riyadh, Saudi \\ Arabia \\ ${ }^{2}$ Department of Urban Planning, King Saud University, Riyadh, Saudi Arabia \\ Correspondence: Waleed S. Alzamil, Department of Urban Planning, College of Architecture and Planning, King \\ Saud University, Saudi Arabia. E-mail: waalzamil@ksu.edu.sa; Nujud Alangari, Department of Architecture and \\ Building Science, College of Architecture and Planning, King Saud University, Saudi Arabia. E-mail: \\ nalangari1@ksu.edu.sa
}

Received: May 7, 2020

Accepted: July 21, $2020 \quad$ Online Published: July 29, 2020

doi:10.5539/jsd.v13n4p115

URL: https://doi.org/10.5539/jsd.v13n4p115

\begin{abstract}
The ministry of housing recently developed a new initiative to support the housing sector in Saudi Arabia, which is the building technology stimulus initiative (BTSI). The needs of this initiative arose due to the high demands of housing units. The importance of the BTSI appears on its ability to reduce the construction period time and to provide a better life cycle with reasonable prices. This paper aims to assess the positive and negative aspects of this initiative in social, economic, and environmental sides. It explains how this initiative can fulfillment the kingdom's vision of 2030. The paper adopts a descriptive analysis of BTSI based on the reports of the Ministry of Housing and the National Vision 2030. The survey was designed to evaluate the economic, social, and environmental dimensions of the BTSI from the perspective of (72) specialists and academics in the scope of housing and building technology. The survey has been analyzed using the SPSS software and the Google Drive charts. The results show that BTSI can help to reduce the period time for housing construction, the use of skilled labor, and increase the high-level professional career opportunities. More, over, The BTSI can provide a healthy environment and reduce visual pollution and waste. In case of mass production, The BTSI contributes to reducing the cost of housing provided by the Ministry of Housing for low-income people. Finally, the paper proposes a gradual transition toward construction technology in the Ministry of Housing projects and the development of policies to motivate the private sector to invest in building technology in partnership with international construction firms.
\end{abstract}

Keywords: affordability, building, housing, Saudi Arabia, technologies, 2030 vision

\section{Introduction}

Rapid urbanization has contributed to increased demand for housing and the spread of slums, informal housing, and shantytowns, especially in Latin America, Asia, Africa, and the Middle East (Bock, Georgoulas, \& Linner, 2012). Goal 11.1 of the Sustainable Development Agenda refers to "ensuring that everyone by 2030 has access to adequate, safe, affordable and basic housing" (UN-Habitat, 2016, p. 13). However, over a billion people worldwide live in substandard housing areas due to the inability to own affordable housing (Mahabir, Crooks, Croitoru, \& Agouris, 2016). This number is expected to increase to more than 2 billion in the next two decades, given the growing urban population (UN-Habitat, 2007). Developing policies to accommodate the urban poor has become very complex. In developing countries, many governments have adopted various policies to address the housing crisis, such as The Housing Financing Fund (HFF) which depends on granting loans to own or improve housing. However, some governments have focused on building housing projects or renewing slums to balance the housing market (Alzamil, 2011). The conditions of developing countries are affected by the rapid global economic changes, and this is reflected in the level of housing demand (Bock, Georgoulas, \& Linner, 2012). Therefore, there is a need to adopt building technologies to provide urgent and high-quality housing.

In developed countries, many governments have responded to technical changes in the construction industry. Japan has made tremendous progress in the construction industry that can reduce housing costs and maintain quality (Bock, Georgoulas, \& Linner, 2012). Jacob (2012) argues that Japan's population is a predominantly aging society 
and labor force wages are high, which has prompted many construction companies to shift toward construction technologies. In contrast, many developing countries are still far from using building technologies widely in housing projects. Developing countries face a challenge in changing the concept of the building industry, which requires the gradual transfer of knowledge.

In Saudi Arabia, the housing issue emerged as a result of urbanization and population growth in major cities associated with the period of the economic boom (1970-1980). The General Authority for Statistics (2020) indicated that the population of Saudi Arabia is estimated at 34,218,169 people in 2020. Moreover, more than 50\% of the population is concentrated in major cities such as Riyadh, Jeddah, Dammam, Mecca, and Medina. The population concentration has contributed to the high demand for housing and the high prices for land and building materials (Alzamil, 2016). The Ministry of Housing has developed many policies and programs to address housing challenges such as a housing program (Sakani) which aims to enable the Saudi family to own a home by providing a range of financing and housing options (Ministry of Housing , 2020). However, Building technology stimulus initiative (BTSI) was launched to support the transformation process from the current construction to the future by investing in advanced technologies and keeping pace with industrial development in a manner that maintains quality and competitive cost.

Building technology stimulus initiative (BTSI) is considered as one of the most important solutions the ministry of housing is trying to domiciliate and develop, due to its ability to address the demand gap for affordable housing units in a reasonable price by stimulating the adoption of innovative building technologies in the construction sector in Saudi Arabia. The widespread development of building technology will be determined by its success at the local level. The building technology initiative is linking four parties together: the investor, the citizen, the contractor, and the building technology factories. The main purpose of this initiative is to transfer the way of constructing buildings from the traditional ways to the new modern building technologies, as well as, to have more investors and to have a high-quality building with reasonable prices (Building Technology, 2019). Building technology helps produce housing units in less than $50 \%$ of the current construction time because most of the manufacturing work is done outside the construction site. The use of by high-quality performance due to continuous monitoring and less cost for the building's life cycle since it will have fewer maintenance prices and unnecessary renovation works. Moreover, it will reduce the use of low skilled labor and implement new high standard jobs. As shown in Figure 1 the need of this initiative emerged due to the increasing demand on housing units which caused the initiative of new building technologies to be developed, since it reduces the time period for constructing a building project and make it easier for Saudi families to have their own houses (BTSI, 2020). Therefore, this paper evaluates the initiative to stimulate construction technology according to environmental, social, and economic considerations within the Kingdom's 2030 vision.

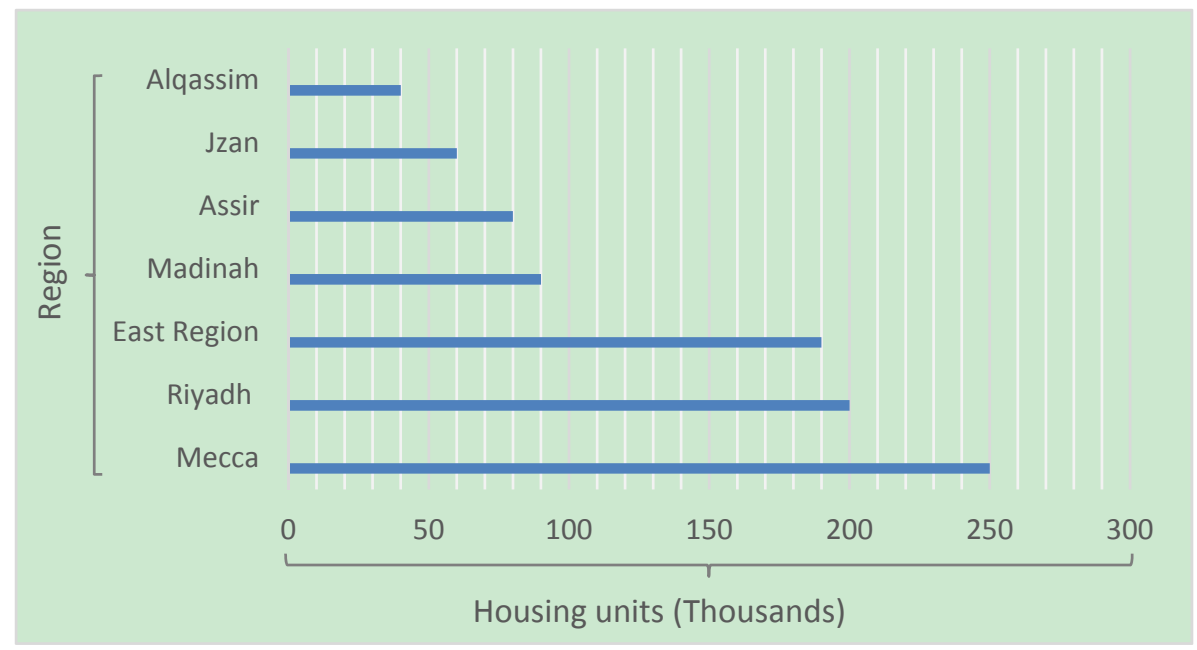

Figure 1. Accumulation of housing demand by 2030

Source: (ministry of housing, 2018)

\subsection{Research Problem}

There are many initiatives and strategic directions that work to help housing affordability and the implementation of proper housing units for Saudi families. Even so, there might be many positive and negative aspects of these 
initiatives, which makes the evaluation of these initiatives is necessary in order to help implement the goals and strategic directions within the kingdom's vision of 2030.

\subsection{Research Importance}

The results of this paper will lead us to know the positive and negative aspects of the building technology initiative offered by the ministry of housing to help housing affordability; and how this initiative is suitable to fulfillment the kingdom's vision of 2030. Also, to know if this initiative will really help the Saudi families to have their own houses that fit with their desires and needs, and to reduce the increasing demands on housing.

\subsection{Research Objectives}

This paper aims to evaluate the building Technology Stimulus Initiative (BTSI) offered by the ministry of housing and how it fits with the kingdom's vision of 2030.

\section{Literature Review}

\subsection{Concept of Building Technology}

The basic definitions of the two terms 'building' and 'technology' according to Merriam Webster are building is "The art or business of assembling materials into a structure" and technology is "practical application of knowledge especially in a particular area" (Dictionary, 2020). In other words, building technology means assembling building parts by using technical processes and methods (O'Sullivan, 2014). Also, modern building technology is basically based on preparing the building parts, walls, and roof outside the building sites in specialized factories, to be ready to install on the site by professions either on concrete or steel structure. As a result, this technique will decrease the time of constructing a building (Alfahad, 2019).

\subsection{The Objectives of Building Technology Stimulus Initiative}

Building Technology Stimulus Initiative (BTSI) comes in response to Vision 2030 for supporting the housing sector through the transition from traditional to modern construction. The initiative aims to enable families to find affordable housing with high quality. The (BTSI) is overseen by the Housing Program, the National Industrial Developments, and Logistics Program, and supported by the Private Sector Stimulus Plan (Building technology, 2020). As shown in Figure 2 this initiative tries to empower the private sector to provide the best housing solutions to meet the needs of families within the framework of the fair market.

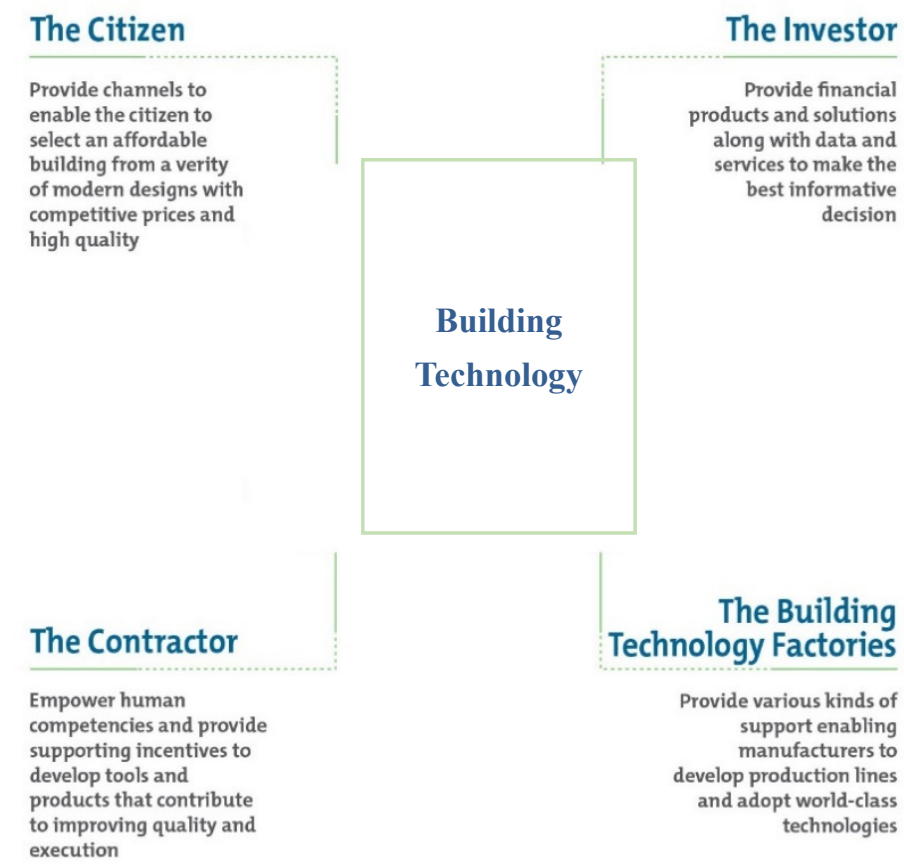

Figure 2. The role of the building technology stimulus initiative (BTSI)

Source: (Building technology, 2020).

According to BTSI (2020), the initiative sets 6 strategic goals focused on the economic, technical, and social 
dimensions. First, economic goals include raising the production capacity of building technology factories, reducing the cost of construction by $5-20 \%$, enhancing the utilization of the local content by $70 \%$, creating 7000 job opportunities, and raising the percentage of local contribution share in GDP. Second, the social goal is to raise the level of satisfaction with building technology products by providing high-quality housing that is compatible with Saudi families. Third, the technical objective is to use building materials and techniques that reduce the implementation time of a residential unit to less than 90 days. As shown in Figure 3 the (BTSI) set a cumulative target of increasing housing units using building technology by 2023. This target is ambitious due to it expected that $50 \%$ of the total 680000 housing units will use building technology.

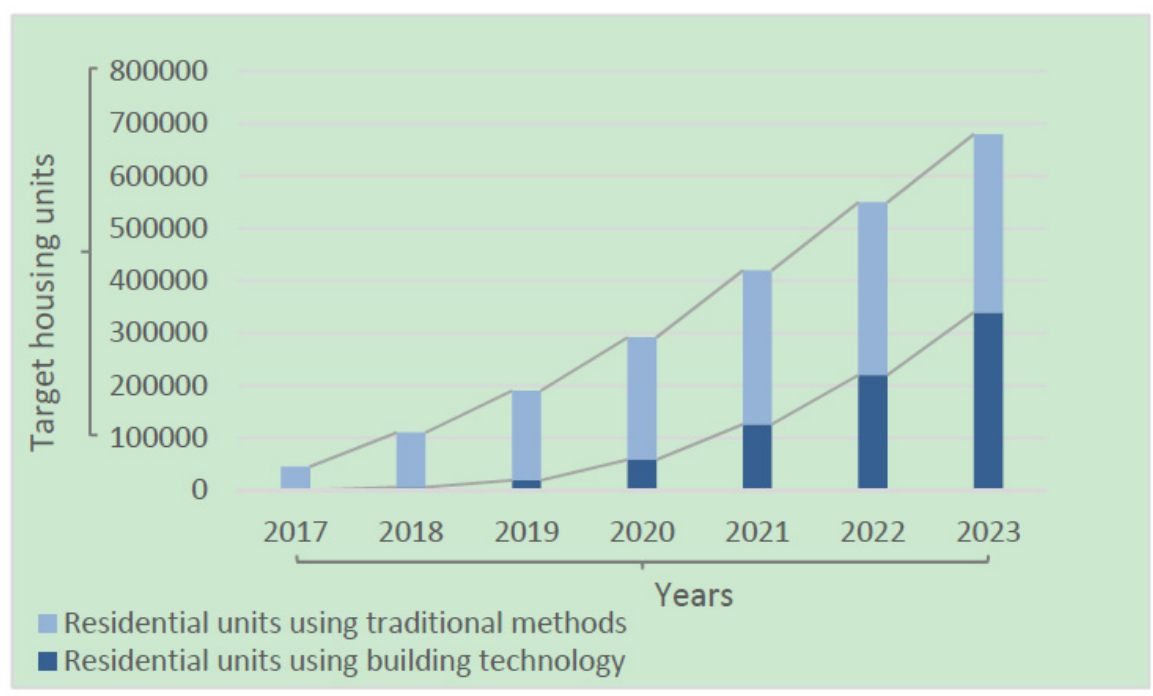

Figure 3. Target cumulative ramp-up of housing units delivery in Saudi Arabia

Source: (Building Technology, 2019, p. 12)

\subsection{Construction Techniques}

There are various types of constructions for all different types of people in society. These include commercial construction, domestic construction, industrial construction, heavy or civil construction, which all need a specific method of technology. Construction methods have been improved all over the years to meet the human needs with high criteria and quality within a reasonable price (Alsulaiman, 2019). Also, there is a wide range of innovative methods that has been used all over the world.

According to Building Technology (2019, p. 16), the most prominent types of building technology adopted by the BTSI in Saudi Arabia are:

[1] Autoclaved Aerated Concrete (AAC), is a lightweight concrete that contains cement limestone and aluminum powder. It is processed in special furnaces and has good thermal insulation. Aerated concrete has the advantages of a lightweight, heat preservation, sound insulation, fire, and mold resistance. However, it is environmentally friendly because it uses industrial waste residue. Moreover, the aerated concrete is flexible and adjustable, which facilitates the electrical wiring and plumbing operations.

[2] Insulated Concrete Forms (ICF), is a system of formwork made of EPS foam that stays in place as a permanent substrate for walls, floors, and roofs. Insulated Concrete Forms (ICF), has the advantages of sound insulation, heat, and improved indoor air quality. Moreover, it resists fire and provides space for accommodate electrical and plumbing installations.

[3] Insulated Precast Systems (IPS), is internally hollow walls and ceilings that are processed in the factory through special molds and transported to the construction site and can be used for internal walls. It is one of the most common construction methods because it provides the safest, fastest, and cheapest construction in the case of mass production.

[4] Light Gauge Steel (LGS), is a high-quality steel structure formed at low temperatures using CNC machines. The pieces are collected form mural structures and roofs installed at the site and extensions are covered with cement plates and then walls are filled with cellular concrete. This type of steel building is popular nowadays 
because it is characterized by durability, strength, and green building perspective. Unlike brick buildings, LGS is an affordable and fast-building material. It is also lightweight and does not rot and resists termite and pest corrosion.

[5] Tunnel Formwork (TF), this system consists of an operation to cast walls and slabs in one operation in one daily cycle. It is a modern construction method that combines low cost, flexibility, speed, quality, and accuracy with off-site manufacturing. Tunnel Formwork is effective in projects for frequent cellular construction such as apartment buildings, hotels, and schools.

[6] Concrete Modular (CM), it is a structural system that consists of composite steel and concrete structural units as all the finishes are implemented in the factory. This system is suitable for designing temporary or rapid housing units such as pilgrims housing, temporary shelter, and refugee housing.

[7] Light Gauge Steel Modular (LGSM), it is a skeleton frame steel column and I-beams, constructed in grids to support the roof and walls of a building and cast in the factory. This method achieves thermal insulation, energy savings, and protects the residence from moisture, mildew, and corrosion.

[8] 3D Printing Technique, this technology depends mostly on programmed work, which built the walls and ceiling with all electrical installation and plumbing pipes, as well as the process of rendering at the same time without the need of human element. In addition, 3D printing is the latest generation of technologies for modern construction methods. As shown in Figure 4 The first house using the 3D printing technique in the middle east has been built in Saudi Arabia. It was built in 25 hours by four Saudis and two foreign experts. The design came in the same style as Saudi homes, with durability in the width of the wall, plumbing materials, and electricity inside the building, adapted to the climate (Alharbi, 2018).

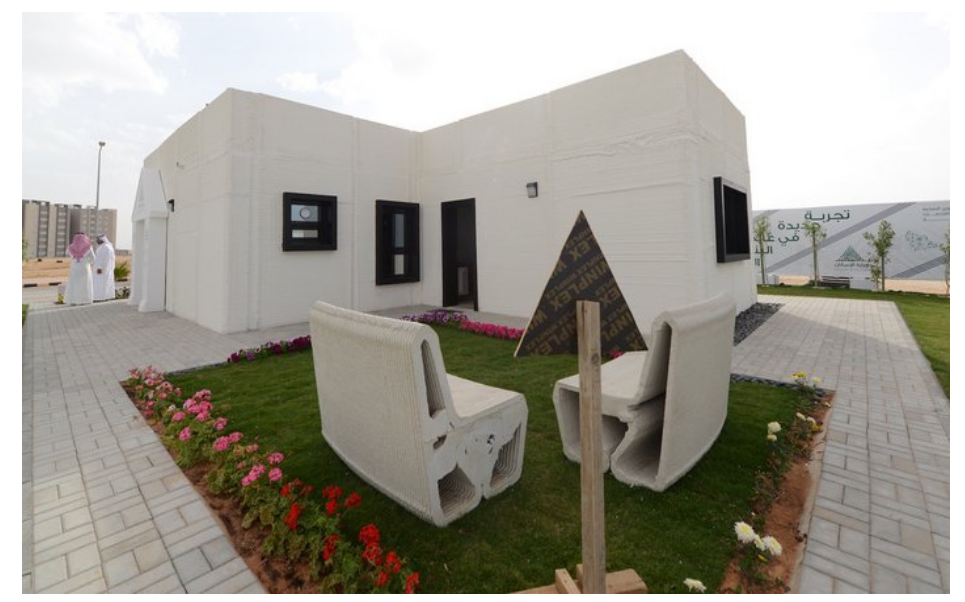

Figure 4. The first house in the Middle East to be built in 25 hours using 3D printing

Source: (Alharbi, 2018).

\subsection{Previous Studies}

\section{"Technology development and implementation of construction in the digital age"}

The digital age has fundamentally shaped the relationship between thought and production and created a direct digital connection between what can be imagined and what can be built through digital information, that can be used in manufacturing and construction to control the machines directly by computers without the need of extra drawings. The system of architecture has been transferred from the traditional system based on human mental and effort to a computer digital system. The digital revolution extended to the construction and implementation process to ensure quick and precise work. The process of manufacturing the structural parts starts directly after designing the building and create a digital model by computer, where digital information, by using specific software, help to choose the suitable structure to be used, as well as manufacturing the structural parts of the building. In the field of architecture, 3D printing was associated with its use in the study of the architectural model. As for construction, it is the process of manufacturing by additive, which consists mainly of layers of materials, and it can be done in two ways: by producing the structure or producing the subcomponents that are assembled to the construction. 3D printing is a useful technique for building a complex geometric shape without the high cost of handwork or the addition of temporary structure, which decreases the amount of time and allows having more flexibility in the design and process implementation. The results are digital manufacturing bridges the gap between representation and construction, which allows the designer to access the new areas that have not been explored, especially for 
free and formally complex forms. Also, there are three processes of production in any digital project. First, after the digital design is done, the project is cut into parts through digital modeling programs to be manufactured by the appropriate technology. Secondly, it's better to manufacture a small model to revise the design. Finally, the production of the building is done through manufacturing the building parts directly, or by using forms of molds to pour the materials in to be assembled in the site (Ismail, 2019).

"The evolution of prefabricated residential building systems in Hong Kong: A review of the public and the private sector"

Prefabrication is a common method in housing projects in Hong Kong, and it has been adopted for over two decades. On the other hand, it has been recently introduced to the private sector. So, this research basically seeks to acknowledge the evolution and application of prefabricated building components in both public and private sectors in high rise buildings in Hong Kong. The detailed analysis of the case studies and face-to-face interviews with building professions have led to these results and conclusions. In general, the most common precast components used were precast façade with a percentage of 51 , and then precast staircase with $22 \%$, then semiprecast slab with $9 \%$ and the least is a semi-precast balcony with $7 \%$. Another outcome is that the use of prefabrication is more common in residential buildings. On the other hand, the use of volumetric precast components is still rare in the building industry. Repeat the prefabrication components is important to achieve cost efficiency. Also, the use of innovative prefabricated components comparing with the old traditional construction illustrates an important advantage, like improving the quality of buildings, reduce the time consumption, reduce waste, dust, and noise of building, and finally decrease the labor attendance on site. In conclusion, this paper demonstrates the advantages of using the prefabrication system in the economic and environmental sectors (Jaillon, 2009).

Table No. 1 summarizes the most prominent types of building technology adopted by the BTSI in Saudi Arabia. according to the literature review, this Table explains the advantages and disadvantages of each method.

Table 1. Comparative analysis of construction techniques

\begin{aligned} & \hline No. \multicolumn{1}{c}{ Method characteristics } \\ & \hline $1 \quad$ Autoclaved Aerated Concrete (AAC) \\ & Advantages Sound insulation, fire resistance, flexible for electrical and plumbing \\ & installations, and economical shipping and handling \\ & Disadvantages \\ & Less energy insulation, the cost is higher than the concrete blocks, and external \\ & walls require weather protection \\ & \hline $2 \quad$ Insulated Concrete Forms (ICF) \\ & Advantages \\ & High bearing capacity, saving 20\% - 30\% of the costs of the concrete structure, \\ & sound and heat insulation, construction speed, 50\% fewer workers, reduced \\ & amount of concrete, increased building life. Disadvantages \\ & Difficulty redesigning, any additions to electricity, or plumbing may also require cutting concrete and may experience problems with humidity. \\ & \hline\end{aligned}


3 Insulated Precast Systems (IPS)

Advantages

Easy to build and install on-site, longer life compared to contemporary construction, high energy efficiency. Also, saving time, uniform the quality of manufacturing parts.

\section{Disadvantages}

IPS needs huge on-site cranes and special transportation for heavy concrete.

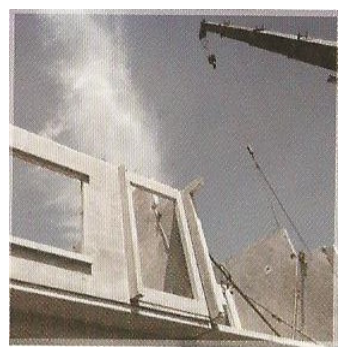
Also, it is difficult to modify a piece of precast concrete.

4 Light Gauge Steel (LGS)

Advantages

Lightweight, highly efficient construction, cost-competitive as well as fast delivery. In addition, the metal structures are not rotting or corrosive and the waste from the manufacturing process can be recycled.

\section{Disadvantages}

It requires extensive experience because the production process is carried out

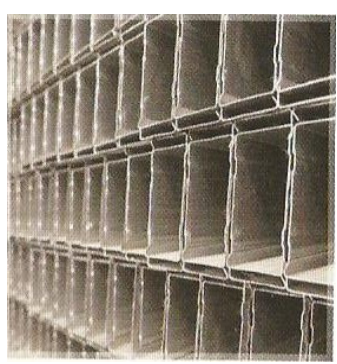
by specialized machines programmed electronically to obtain metal sections with accurate measurements

5 Tunnel Formwork (TF)

Advantages

Implementation speed, high quality, the low economic cost in case of large projects or residential complexes, high durability, and earthquake resistance.

Disadvantages

It does not provide flexibility in design, requires trained labor, concrete walls

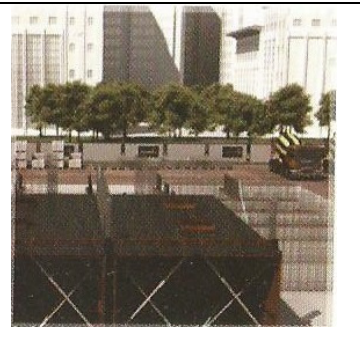
do not suit hot climates, expansion cracks, and heat shrinkage due to the difference in the thermal impact on the external walls.

6 Concrete Modular (CM)

\section{Advantages}

High durability, easy transportation, short building time for construction of up to two months, and installation of the building on-site within a few days.

\section{Disadvantages}

The cost depends on the volume of production, depends on the production lines for ready designs.

7 Light Gauge Steel Modular (LGSM)

\section{Advantages}

Lightweight, supports fast construction, this construction is not able to rot or corrode.

\section{Disadvantages}

Economically, it needs huge production lines to expand supply. Any defect in

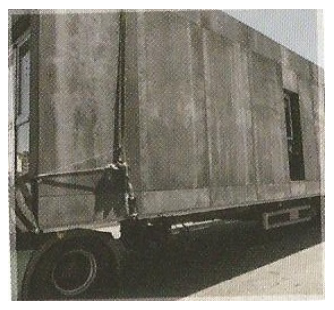
manufacturing an inaccurate component may delay the project. 
8 3D Printing Technique

Advantages

Depend on a few labors, inexpensive, suitable in mass production as frequent housing projects. Moreover, this technology adapts to the environment and climatic conditions.

\section{Disadvantages}

Its success depends on mass production, it does not provide multiple options compared to contemporary construction.

Authors depending on: (Building Technology, 2019, p. 16), (What is Lightweight Concrete?, n.d.), (Polywall, n.d.), (Sedlacek, 2015), (What is Lightweight Concrete?, n.d.), (PCA, 2019); (3D printing in construction, 2019).

\section{Methodology}

This paper adopts a descriptive method by reviewing the housing of ministry plans in Saudi Arabia and connect them to the National Vision of 2030. In addition, a survey distributed to the specialists and the academics related to housing and building technology. The questions of the survey will connect the building technology initiative with the Kingdom's Vision of 2030. Therefore, the study focuses on reviewing and evaluating positive and negative aspects of the building technology initiative and how it benefits the housing sector in the Kingdom of Saudi Arabia. For this reason, the study has been divided into three main cores which are the social, economic, and environmental aspects within the Kingdom's Vision of 2030. Therefore, the analysis of each core will include theoretical and descriptive analysis from the information that the Ministry of Housing and the BTSI has provided. Furthermore, it will include information from the survey that has been distributed to determine if the initiative has met the goals of the Kingdom's Vision of 2030.

\subsection{Survey Design}

This survey has been designed to evaluate the three cores of the initiative. Therefore, it has been divided into two main parts. The first one is the general information that includes the age, career, experience, qualification, work field, and work nature of the sample. The second part includes the survey cores. The survey has been analyzed using the SPSS program and the Google Drive charts.

\subsection{Sample Selection and Size}

Since the building technology initiative is a new technique in the building industry in Saudi Arabia, there are not many people owned houses by this technology. Therefore, the survey has been distributed between specialists and academics who related to the field of housing and building technology. Moreover, the sample size is 72 , the confidence level is $95 \%$, the confidence interval is 11.55 and the percentage is $50 \%$.

\subsection{Survey Sample Analysis}

According to the survey, most of the samples are aged between $30-40$; they constitute $36 \%$ of the total sample. In contrast, $11 \%$ are aged between 60-70. Moreover, people aged between 40-50 and 20-30 are equal in the percentage of $18 \%$. On the other hand, approximately $62.5 \%$ of the samples are specialist and the rest is academic. The experiences of most of the samples are more than 20 years. In addition, $44 \%$ of the sample has a bachelor's degree, whilst only $2.8 \%$ have a diploma; $33 \%$ of the sample are master's degree holders, and $19 \%$ are Ph.D. holders. As shown in Figure 5 the samples who work on the public sector have got $65 \%$ of the total. While the business owners are $15.3 \%$ and the private sector is $19.4 \%$. Finally, Figure 6 shows the work nature percentage for the samples. $31.9 \%$ of the study sample works in the field of architecture and building sciences, $27.8 \%$ in the construction and consulting sector, and $22.2 \%$ work in the field of urban planning and design. 


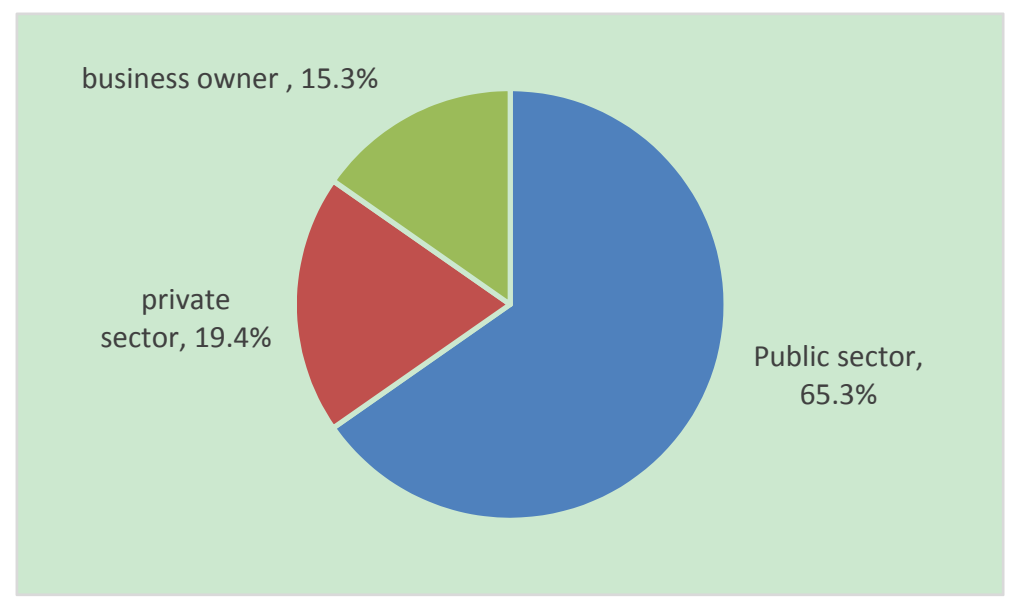

Figure 5. Work field

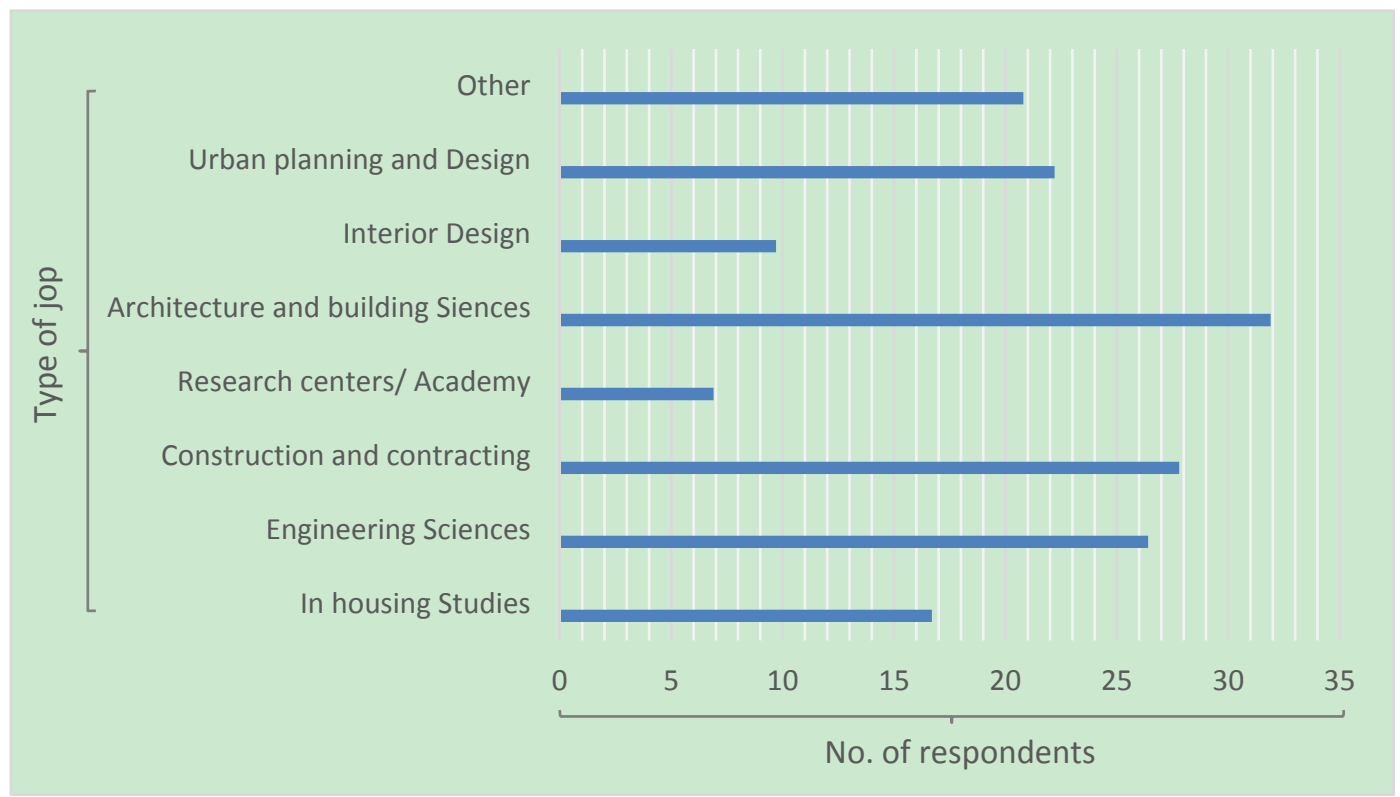

Figure 6. Work nature

\section{Results}

This part summarizes the result of the studies. Each core of the study has been evaluated separately. The average is calculated based on the Likert scale (5: strongly agree, 4: agree, 3: neutral, 2: disagree, 1: strongly disagree).

\subsection{Social Aspects}

These aspects explain the extent to which the Building Technology Initiative has achieved the creation of a positive social life in which citizens have a good quality of life in a way that achieves the kingdom's vision of 2030. Therefore, according to the Ministry of Housing, this initiative will provide better quality houses due to the manufacturing process standards that have continuous monitoring (ministry of housing, 2018). The survey consists of 6 questions that measure the social aspects of the BTSI related to the Kingdom's Vision of 2030 for the housing sector. According to the SPSS program, Table 2 shows the percentage of each answer. In summary, $84.7 \%$ of the people agreed about how building technologies help to reduce the time of construction. Whilst, the highest disagree was about how the initiative can contribute to providing financially adequate housing for families which got $16.7 \%$ disagreement only. The difference between the agreement and disagreement in most of the questions are high, so the higher percentages go mostly to the agreement answers. 
Table 2. Social aspects results

\begin{tabular}{|c|c|c|c|c|c|c|c|}
\hline \multirow[t]{2}{*}{ \# } & \multirow[t]{2}{*}{ Social variables } & \multicolumn{5}{|c|}{ Percentage } & \multirow[b]{2}{*}{$\begin{array}{c}\text { Average } \\
(1-5)\end{array}$} \\
\hline & & 5 & 4 & 3 & 2 & 1 & \\
\hline 1 & $\begin{array}{l}\text { BTSI reduce the time for housing construction, which } \\
\text { achieves social satisfaction }\end{array}$ & 23.6 & 61.1 & 12.5 & 2.8 & 0 & 4.0 \\
\hline 2 & $\begin{array}{l}\text { BTSI helps to find suitable housing at a lower cost and } \\
\text { higher life cycle }\end{array}$ & 25 & 44.4 & 16.7 & 12.5 & 1.4 & 3.7 \\
\hline 3 & BTSI contributes to providing healthy housing for families & 15.3 & 48.6 & 25 & 9.7 & 1.4 & 3.6 \\
\hline 4 & $\begin{array}{l}\text { BTSI can provide housing that meets the social } \\
\text { requirements of families }\end{array}$ & 26.4 & 47.2 & 18.1 & 8.3 & 0 & 3.9 \\
\hline 5 & $\begin{array}{l}\text { BTSI provide financially adequate housing for all the } \\
\text { society }\end{array}$ & 25 & 40.3 & 18.1 & 15.3 & 1.4 & 3.7 \\
\hline 6 & $\begin{array}{l}\text { BTSI can meet the standards for natural ventilation, } \\
\text { heating, and natural lighting requirements that achieve a } \\
\text { better social life. }\end{array}$ & 31.9 & 43.1 & 13.9 & 9.7 & 1.4 & 3.9 \\
\hline
\end{tabular}

Source: Authors.

Note: (5: strongly agree, 4: agree, 3: neutral, 2 : disagree, 1 : strongly disagree)

\subsection{Economical Aspects}

These aspects explain the contribution of the Building Technology Initiative in providing job opportunities for citizens, diversifying the economy, and increasing investment to achieve the Kingdom's Vision 2030. The building technology is a good choice for the economics of the country because it reduces the cost of a life cycle of the building around $10 \%$ due to low-cost maintenance, and there is no short term need for restoration and improvement. Also, it can reduce the dependence of limited skilled labor. However, lower costs depend on the availability of the mass production lines for construction technology and widespread demand. Building technology can build broad investment relationships with more than 400 building technology providers around the world (Building Technology Stimulus Initiative, n.d.). The survey shows results about the economic aspects based on 10 points that relate to the kingdom's vision 2030. According to Table 3, most of the answers were more than $50 \%$ agree. The most disagreement was about the reduction of life cycle costs which got 18.1 disagreements. 
Table 3. Economical aspects results

\begin{tabular}{|c|c|c|c|c|c|c|c|}
\hline \multirow[t]{2}{*}{ \# } & \multirow[t]{2}{*}{ Economic variables } & \multicolumn{5}{|c|}{ Percentage } & \multirow[b]{2}{*}{$\begin{array}{c}\text { Average } \\
(1-5)\end{array}$} \\
\hline & & 5 & 4 & 3 & 2 & 1 & \\
\hline 1 & BTSI can reduce the use of limited skilled labor. & 30.6 & 47.2 & 13.9 & 6.9 & 1.4 & 3.9 \\
\hline 2 & $\begin{array}{l}\text { BTSI encourages the creation of high-level professional } \\
\text { career opportunities. }\end{array}$ & 19.4 & 43.1 & 20.8 & 15.3 & 1.4 & 3.6 \\
\hline 3 & BTSI reduces the costs of electricity and water bills. & 20.8 & 44.4 & 23.6 & 11.1 & 0 & 3.7 \\
\hline 4 & $\begin{array}{l}\text { BTSI reduces the life cycle costs of the building due to the } \\
\text { low maintenance cost. }\end{array}$ & 18.1 & 40.3 & 23.6 & 18.1 & 0 & 3.5 \\
\hline 5 & $\begin{array}{l}\text { BTSI contributes to reducing the cost of affordable housing } \\
\text { provided by the Ministry of Housing for low-income people }\end{array}$ & 16.7 & 48.6 & 18.1 & 12.5 & 4.2 & 3.6 \\
\hline 6 & $\begin{array}{l}\text { BTSI increases the chances of providing various housing } \\
\text { alternatives that suit the financial capacity of families }\end{array}$ & 26.4 & 47.2 & 16.7 & 8.3 & 1.4 & 3.8 \\
\hline 7 & $\begin{array}{l}\text { BTSI could contribute to the localization of building } \\
\text { technology for housing construction. }\end{array}$ & 16.7 & 51.4 & 20.8 & 9.7 & 1.4 & 3.7 \\
\hline 8 & BTSI supports investors. & 18.1 & 56.9 & 16.7 & 6.9 & 1.4 & 3.8 \\
\hline 9 & $\begin{array}{l}\text { BTSI encourages developers to reach local building } \\
\text { technology providers. }\end{array}$ & 16.7 & 62.5 & 12.5 & 5.6 & 2.8 & 3.8 \\
\hline 10 & $\begin{array}{l}\text { BTSI facilitates networking with building technology } \\
\text { companies around the world. }\end{array}$ & 15.3 & 61.1 & 15.3 & 5.6 & 2.8 & 3.8 \\
\hline
\end{tabular}

Source: Authors.

Note: (5: strongly agree, 4: agree, 3: neutral, 2: disagree, 1: strongly disagree)

\subsection{Environmental Aspects}

As shown in Table 4 the building technology stimulus initiative has many environmental aspects in line with the objectives of the Kingdom's Vision 2030. According to the survey analysis, the first four points have an agreement of more than $60 \%$. On the other hand, $40.3 \%$ were neutral about the initiative uses renewable sources, whilst $47.2 \%$ were agreed.

Table 4. Environmental aspects results

\begin{tabular}{llcccccc}
\hline$\#$ & Environmental variables & \multicolumn{7}{c}{ Percentage } \\
\cline { 2 - 8 } & & 5 & 4 & 3 & 2 & 1 & $\begin{array}{c}\text { Average } \\
(1-5)\end{array}$ \\
\cline { 2 - 8 } 1 & & & & & & & 3.7 \\
2 & BTSI can contribute to reducing the environmental pollution. & 19.4 & 50 & 15.3 & 13.9 & 1.4 & 3.7 \\
& BTSI can contribute to providing a healthy environment and & 12.7 & 55.3 & 18.3 & 12.7 & 0 & 3.6 \\
& housing for families. & & & & & & \\
3 & BTSI promotes the principle of reducing energy waste. & 20.8 & 45.8 & 20.8 & 12.5 & 0 & 3.7 \\
4 & BTSI contributes to reducing visual pollution and waste & 16.7 & 47,2 & 19.4 & 13.9 & 2.8 & 3.6 \\
& generated by traditional construction. & & & & & & \\
5 & BTSI uses renewable energy generation tools. & 12.5 & 34.7 & 40.3 & 11.1 & 1.4 & 3.4 \\
6 & BTSI works to reduce environmentally harmful materials. & 14.1 & 35.2 & 36.6 & 12.7 & 1.4 & 3.4 \\
\hline
\end{tabular}

Source: Authors.

Note: (5: strongly agree, 4: agree, 3: neutral, 2: disagree, 1: strongly disagree) 


\section{Conclusion}

As shown in Table 5 BTSI contributes to the vision of 2030 positively. There are $61 \%$ of the sample agreed about how this technology reduces the time in construction which will lead to help the ministry of housing in providing more units in a short time. As a result, the demand for housing units will decrease and this will help to implement the Kingdom's vision of 2030. According to the results, this initiative will contribute to providing more opportunities and jobs for Saudis and increasing the investment. Also, it will help in diversifying the economy which will lead to achieving the vision of 2030 . According to the analysis, $40 \%$ of the sample are neutral about using renewable energy generation tools and $36.6 \%$ are neutral about how this technology can reduce environmentally harmful materials. Finally, the results indicate the importance of the gradual use of this building technology in future housing in Saudi Arabia.

Table 5. Summary of BTSI evaluation within the Kingdom's Vision 2030

\section{1-Social Aspects}

Reduce the period time for construction and provide high life cycle units with low costs that meet the social desires and needs of families.

Provide healthy housing units for families

Provide housing units that are financially adequate to all types of society.

Meet the standards for natural ventilation, heating, and lighting that achieve a better social life.

\section{2-Economical aspects}

Reduce the use of limited skilled labor and increase high-level professional career opportunities.

Reduce the costs of electricity and water bills.

Reduce the maintenance of building which lead to a decrease in the life cycle cost.

Reduce the cost of affordable housing provided by the Ministry of Housing for low-income people.

Provide different alternative units to meet the different financial capacity of families.

Localize the building technology for housing construction.

Support investors.

Encourage developers to reach local building technology providers.

Help networking with building technology companies around the world.

3-Environmental Aspects

Reduce environmental pollution

Provide a healthy environment and housing units for families.

Reduce energy waste.

Reduce visual pollution and waste.

\section{Recommendations}

Based on the results of the study that explain the effect of BTSI from the social, economic, and environmental sides, there are some recommendations to enhance the positive aspects of BTSI as a following:

[1] Providing awareness of the importance of this technology for the specialist and the advantages of using advanced building technology to enhance the building industry.

[2] Developing the building technology industry sector with high standards and quality.

[3] Developing regulations and standards to control the negative impact of this technology. These standards include the type of materials used, the quality of the materials, the sustainability, and the costs of the materials.

[4] Providing regulations for the factory owners to control the construction industry market.

[5] Providing incentives or tax exemptions to beneficiaries of housing subsidies to use construction technology as an alternative to existing construction. 


\section{Acknowledgments}

The authors acknowledge the Saudi Housing Research Unit at the College of Architecture and Planning, King Saud University for providing supporting in publishing this article in this journal.

\section{References}

Alfahad, A. (2019). Construction trip from caves to 3D. localities.

Alharbi, E. (2018). The first house in the Middle East to be built in 25 hours using 3D printing. sabq.

Alsulaiman, K. (2019). Building technologies and future stimulus initiative. okaz.

Alzamil, W. (2011). The Experiences of Governments in Dealing with Squatter Settlements. Saarbrücken: LAP LAMBERT Academic.

Alzamil, W. (2016). Evaluation of Affordable Housing and Subsidy Programs in Saudi Arabia. Saarbrücken: LAP LAMBERT Academic Publishing.

Bock, T., Georgoulas, C., \& Linner, T. (2012). Advanced Construction and Building Technology for Society. München: Laboratory of Building Realization and Robotics,Technische Universität München (TUM), Germany.

BTSI. (2020). Building Technology Stimulus Initiative. Retrieved from https://www.housing.gov.sa/en/initiative/btsp

Building Technology. (2019a). Building Technology. Retrieved from https://www.btsi.gov.sa/en/

Building Technology. (2019b). Investing in Building Technology. Riyadh: Building Technology.

Building technology. (2020). Building technology. Retrieved from https://www.btsi.gov.sa/

Designing Buildings. (2019, July 26). $3 D$ printing in construction. Retrieved from https://www.designingbuildings.co.uk/wiki/3D_printing_in_construction

General Authority for Statistics. (2020). General Authority for Statistics. Retrieved from https://www.stats.gov.sa/en

Ismail, A. S. (2019). Technology development and implementation of construction in the digital age. Journal of Engineering Sciences.

Jacob, F. (2012). Automated Construction - An efficiency analysis and the socio-economic impact. München: Laboratory of Building Realization and Robotics,Technische Universität München (TUM), Germany.

Jaillon, L. (2009). The evolution of prefabricated residential building systems in Hong Kong: A review of the public and the private sector. Automation in Construction, 239-248. https://doi.org/10.1016/j.autcon.2008.09.002

Mahabir, R., Crooks, A., Croitoru, A., \& Agouris, P. (2016). The study of slums as social and physical constructs: Challenges and emerging research opportunities. Regional Studies, Regional Science, 399-419. https://doi.org/10.1080/21681376.2016.1229130

Merriam Webster. (2020). Dictionary. Retrieved from: https://www.merriam-webster.com/dictionary/building

Ministry of housing. (2018). Strategic goals. Retrieved from https://housing.gov.sa/ar/about-housing/2

Ministry of Housing. (2020). Sakani Program. Riyadh: Ministry of Housing.

Ministry of Housing. (n.d.). Building Technology Stimulus Initiative. Retrieved from https://www.housing.gov.sa/ar/initiative/btsp

O'Sullivan, L. (2014). What is 'Building Technology? constructionspecifier.

PCA. (2019). Portland Cement Association. Retrieved from https://www.cement.org

Polywall. (n.d.). Below Grade Complete Waterproofing System Products. Retrieved from https://polywall.com/waterproofing-system/

Sedlacek, M. (2015). Tunnel Form Construction. Atlas.

The Constructor. (n.d.). What is Lightweight Concrete? Retrieved from https://theconstructor.org/

UN-Habitat. (2007). Slum Dwellers to double by 2030. Nairobi, Kenya: UN-Habitat.

UN-Habitat. (2016). Urbanization and development. Nairobi, Kenya: United Nations Human Settlements Programme (UN-Habitat). 


\section{Copyrights}

Copyright for this article is retained by the author(s), with first publication rights granted to the journal.

This is an open-access article distributed under the terms and conditions of the Creative Commons Attribution license (http://creativecommons.org/licenses/by/4.0/). 